\title{
Boletín
}

Criminológico

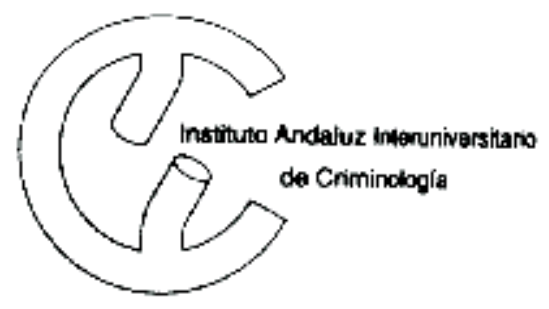

Directora: Elisa García España.

Coordinadora: Juan Carlos Rojo García

Publicado por la Sección de Málaga del IAIC

Edificio Institutos de Investigación, Universidad de

Málaga. Campus de Teatinos, 29071 MALAGA

Tel:(95) 2132325 - Fax:(95) 2132242

Depósitolegal: MA 857/1996ISSN:1137-2427

www.uma.es/estudios/propias/criminologia

El sistema de justicia penal juvenil ha sido objeto de una profunda transformación mediante la aprobación en la última legislatura de la L.O. 5/2000 de Responsabilidad penal de los menores.

Cualquier legislación que pretenda ser efectiva debe tener muy en cuenta la realidad social sobre la que pretende incidir, lo que no es seguro que se haya atendido en este caso.

El trabajo que en este número del Boletín Criminológico se presenta abarca esa realidad en la Comunidad Autónoma de Castilla-La Mancha, dándonos a conocer la magnitud del problema de los jóvenes y menores infractores de la norma penal, tanto en sus aspectos cuantitativos como cualitativos.

Es de lamentar el escaso número de investigaciones sobre esta problemática en las diferentes Comunidades autónomas, carencia que resulta especialmente clara en Andalucía. De ahí que resulte de interés dar a conocer las investigaciones disponibles.

\section{EL RETO DE LA NUEVA JUSTICIA DE MENORES}

\section{INTRODUCCIÓN}

La nueva L.O. 5/2000 reguladora de la responsabilidad penal de los menores va a implicar algunas reformas importantes en el ámbito de la justicia de menores; una de ellas es el rango de edad de aplicación de la misma.

Hasta ahora la jurisdicción de menores abarcaba desde los 12 a los 15 años. Con la nueva Ley, por un lado, los menores de 14 años no serán susceptibles de judicialización y, por otro, entran en esta jurisdicción individuos de 16 y 17 años que hasta ahora eran considerados como adultos en cuanto a su responsabilidad criminal (artículo 1 de la L.O. 5/ 2000). Aunque el intervalo total de edad se mantiene igual (4 años), es de prever que el cambio de los más pequeños por los de más edad suponga una signifi- cativa modificación tanto cuantitativa como cualitativa de los sujetos que son susceptibles de comparecer ante la jurisdicción de menores.

Si hablamos de los aspectos cuantitativos, éste será un cambio importante. Todos los datos que existen sobre delincuencia juvenil así lo indican; los adolescentes comienzan a delinquir entre los 1012 años y la prevalencia aumenta gradualmente hasta alcanzar un máximo a los 17-18 años, para, a partir de dicha edad, empezar una disminución gradual. Así, cabe esperar que el número de menores que se incorporen a la jurisdicción de menores sea muy superior al de los que la abandonen.

Además, este cambio será también cualitativo, pues el tipo de delito no va a ser el mismo en el

\section{Autores:}

Cristina Rechea Alberola Esther Fernández Molina

caso de los sujetos de 12-13 años que en el caso de los de 16-17 años.

Pero es más, la nueva Ley prevé que parte de los sujetos de 1820 años, que teóricamente pertenecen a la jurisdicción de adultos, puedan pasar también a la jurisdicción de menores (artículo 4 de la L.O. 5/2000). Si el nuevo sistema de justicia juvenil se va a hacer cargo, en algunas ocasiones, de estos jóvenes de 18 hasta 21 años, es urgente saber cuántos serán y cómo se debe actuar con ellos, porque está claro que, en lo que se refiere a intervención, ésta ha de ser muy diferente respecto a la que se lleva a cabo con los chavales de 14 años.

La Comunidad de Castilla-La Mancha ha sentido la necesidad de tener datos suficientes para

\section{Boletín Criminológico $N^{o} 47$ Mayo-Junio 2000 Página 1}


hacer una previsión del aumento de casos que van a sufrir los Juzgados de Menores y pronosticar con qué tipo de personas hay que contar a la hora de prestarles su asistencia, encargándose la Universidad de Castilla-La Mancha de hacer el estudio en dicha comunidad.

\section{RESULTADOS \\ CUANTITATIVOS}

De los 57.035 expedientes revisados se encontraron un total de 11.287 individuos en el rango de edad de 12 a 20 años . A partir de estos datos se pueden hacer ciertas afirmaciones que servirán de base para la cuantificación del fenómeno y la valoración de su incidencia en el sistema de justicia juvenil. Por ejemplo, por lo que respecta a la evolución del fenómeno delictivo en este grupo de población, parece que se da una tendencia a la estabilidad: El volumen de los casos enjuiciados es similar cada año, si bien habría que matizar que las tendencias difieren levemente según el grupo de edad que se considere; así, en el grupo de menor edad parece que hay una tendencia a disminuir levemente mientras que entre los mayores la tendencia es a ser cada año unos pocos más.

En relación con la variable sexo los resultados del estudio muestran conclusiones similares a las del resto de estudios empíricos que hay sobre la materia: la delincuencia es eminentemente masculina, tan sólo un $12 \%$ de los enjuiciados son mujeres. No obstante, entre las mujeres, son las más jóvenes las que delinquen más; así en el grupo de edad 12-
13 años delinque un porcentaje del $17 \%$, en el de $14-15$ años este porcentaje es algo menor, un $15,2 \%$, descendiendo conside rablemente en edades mayores; $\mathrm{el}$ porcentaje es especial mentebajo en jóvenes de 17 y 18 años, un $7,6 \%$ y un $8,3 \%$ respectivamente, elevándosea los 19 y 20 años a un $13 \%$ y un $14 \%$ respectivamente, pero sin llegar aigualar los porcentajes delas más jóvenes.

Enel gráfico referentealava riable edad, secompruebaquela tasa desujetosaumentagradualmente desdelos 12 hastalos 16 años, alcanzando abruptamente un máximo alos 17 años, y desde ese punto se iniciaun descenso, menos pronunciado queel anterior ascenso, pero consis- tente. Estos datos coinciden con otras investigacionessobredelincuencia

\section{METODOLOGÍA}

Para cuantificar el número de jóvenes que podrían incorporarse a la futura jurisdicción de menores se localizó a aquellos jóvenes de 14 a 20 años que hubieran estado inmersos en un proceso judicial durante un período de dos años y medio (entre junio 1996 -fecha en que entra en vigor el nuevo C.P.y diciembre 1998). Esta información se obtuvo de la totalidad de los tribunales de justicia de la región; esto es, Juzgados de Menores, Juzgados de lo Penal, Audiencias Provinciales y una muestra representativa de los Juzgados de Instrucción (13 Juzgados de los 66 existentes). El muestreo de los Juzgados de Instrucción se estratificó en cada una de las provincias en atención de las condiciones socioeconómicas de las mismas.

\begin{tabular}{|c|c|c|c|}
\hline JURISDICCIÓN & FUENTE DE INFORMACIÓN & MUESTRA & ERROR MUESTRAL \\
\hline $\begin{array}{l}\text { JUZGADOS DE } \\
\text { INSTRUCCIÓN }\end{array}$ & $\begin{array}{c}\text { Diligencias previas con las que se inici } \\
\text { el proceso y sentencias penales que } \\
\text { enjuician las infracciones más leves }\end{array}$ & $\begin{array}{c}13 \text { Juzgados } \\
18 \text { ' } 44 \% \\
\text { del total }\end{array}$ & $\begin{array}{c}\text { ERROR: O'01\% } \\
\text { NIV. CONFIANZA } \\
99\end{array}$ \\
\hline $\begin{array}{c}\text { JUZGADOS DE } \\
\text { LO PENAL }\end{array}$ & $\begin{array}{c}\text { Sentencias penales con las que } \\
\text { concluye el proceso }\end{array}$ & $100 \%$ & Ningún error \\
\hline $\begin{array}{c}\text { AUDIENCIA } \\
\text { PROVINCIAL }\end{array}$ & $\begin{array}{c}\text { Sentencias penales con las que } \\
\text { concluye el proces }\end{array}$ & $100 \%$ & Ningún error \\
\hline $\begin{array}{c}\text { JUZGADOS DE } \\
\text { MENORES }\end{array}$ & Expedientes de Reforma & $100 \%$ & Ningún error \\
\hline
\end{tabular}


autoinformada realizadas a escala nacional y regional, que indican que el punto álgido de la delincuencia juvenil se da entre los 15 y 17 años y que a partir de ese momento se inicia el descenso. Lo que no está tan claro es el abrupto salto entre los sujetos de 16 y los de 17 años. Ambos grupos pertenecen hasta ahora a la jurisdicción de adultos, pero los de 16 presentan una frecuencia delictiva más parecida a los de 15 , que pertenecen a la jurisdicción de menores, que a los de 17. Este es un dato que merece algo más de atención, pues podría ser un índice de lo difícil que resulta establecer un corte tajante entre ambas jurisdicciones o, simplemente, de que la escuela funciona como mecanismo de control social informal, puesto que la edad de escolarización obligatoria llega hasta los dieciséis años.

A pesar del descenso paulatino de la población juvenil en los últimos años, la estabilidad del número de casos enjuiciados nos permite utilizar con garantías los datos del año 1998, que es el más próximo al 2001 (año de la entrada en vigor de la L.O. 5/2000), para estimar la magnitud del nuevo sistema de justicia juvenil.

En Castilla-La Mancha, el número de expedientes tramitados en 1998 por todos los Juzgados de Menores de la región fue de 1051 , lo que representa un $1,26 \%$ de la población de esa comunidad que tenía entre 12 y 15 años en ese momento. De este número, 713 corresponden a los sujetos de 14 a 15 años.

En el recuento realizado en la jurisdicción de adultos se encontraron, en el año 1998, 1959 expedientes de sujetos que tenían, en el momento de cometer el de-

\section{Sujetos enjuiciados distribuidos por edad datos de Castilla-La Mancha, 1998}

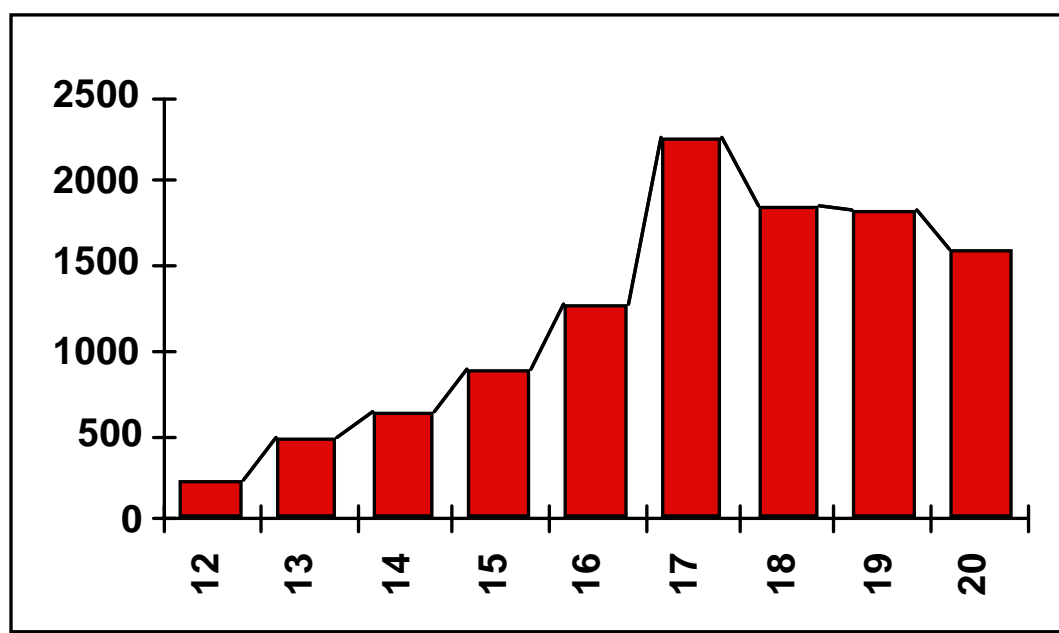

lito, entre 16 y 17 años (621 de 16 años y 1338 de 17 años). Este número supone un incremento del $190 \%$ sobre el actual volumen de los Juzgados de Menores. Si además incluimos el número de expedientes de sujetos de 14 y 15 años comentado en el párrafo anterior, tendremos que el volumen de trabajo de los Juzgados de Menores aumentará en un $259 \%$ en el momento de la entrada en vigor de la nueva Ley; esto es, por cada 100 casos que se tramitan ahora en los Juzgados de Menores, habrá en el futuro 259 casos. Y esto, teniendo en cuenta sólo los casos que indefectiblemente tendrán que ser tramitados por los Juzgados de Menores. Esto es lo que hemos denominado hipótesis mínima. Con estos datos, el porcentaje de expedientes que los Juzgados de Menores resolverán en un año supondrá el 3\% de la población general de sujetos entre 14 y 17 años.

Por otro lado, cierto número de sujetos entre 18 y 20 años podrán remitirse a la jurisdicción de menores si cumplen los requisi- tos de no reincidencia y de no gravedad del hecho delictivo que establece el artículo 4 de la Ley. El estudio revela que 2668 estarían en condiciones de incorporarse a los Juzgados de Menores. Este dato debe matizarse siempre a la baja, ya que según el propio tenor literal de la Ley la remisión a la jurisdicción de menores atenderá también a las circunstancias personales del imputado. El volumen de casos de esta hipótesis máxima supone un 3,25\% de la población entre 14 y 20 años.

Respecto a estos datos, hay que tener en cuenta que hacen referencia al número de sujetos a los que se les incoará expediente en los diferentes Juzgados de Menores de la región, que es el dato que interesa a la Administración de Justicia para las previsiones, tanto de personal como de infraestructuras. Por el contrario, teniendo en cuenta los datos relativos a las historias criminales, se puede determinar el número real de sujetos que van a ser objeto de una actuación por parte de este nuevo sistema. De esta forma, la hipótesis mínima inicial quedaría re- 
ducida a 2.318 sujetos y la máxima a 4.532; estos serían los datos que interesan a los encargados de la intervención y que determinan el volumen exacto de población de jóvenes y menores delincuentes.

\section{ASPECTOS CUALITATIVOS}

En relación a la tipología delictiva no hay apenas diferencias entre las distintas edades en los que estos sujetos están distribuidos.

Las categorías con mayor prevalencia son las de los delitos contra las personas y contra el patrimonio; todas las demás, excepto contra la seguridad colectiva y contra el orden público, no llegan a una prevalencia del $5 \%$ y aun en éstas sólo se da de una manera significativa a partir de los 17 años, lo que implica que son tipos de delitos a los que no están muy acostumbrados en la actual Justicia de Menores. De estas categorías, tres de ellas, contra las personas, contra la seguridad colectiva y contra el orden público, manifiestan una tendencia al alza con la edad, y sólo en los delitos contra el patrimonio la tendencia es a la baja. Para las demás categorías, la tendencia general es a la baja con la edad.

Otro aspecto importante en la definición de la delincuencia juvenil futura es el de la reincidencia, ya que ésta va a ser determinante a la hora de decidir si un sujeto va a permanecer en la jurisdicción de adultos o no. Con todo, la lenta maquinaria de la justicia de adultos produce en ocasiones situaciones paradójicas y así, hemos podido constatar en la recogida de datos que hay sujetos que delinquen una y otra vez y, sin em- bargo, aparecen como delincuentes primarios en los expedientes.

Centrándonos en los sujetos que tenían antecedentes penales por haber recaído sobre ellos una sentencia penal firme, los datos contradicen la idea tradicional de que son siempre los mismos los que delinquen. Es cierto que los porcentajes aumentan a partir de los 16-17 años, pero incluso entonces el porcentaje de sujetos que no reincide es también alto. Este último dato afectará seriamente a la Administración de Justicia, en concreto a la Fiscalía de Menores, que es la receptora de los jóvenes sean o no enjuiciados, porque deberá incoar un expediente por cada uno, y al Equipo Técnico, que deberá pronunciarse en cada ocasión sobre los aspectos psicosociales del menor. Por otra parte el hecho de que exista un número tan alto de delincuentes primarios es un dato que la Administración Autonómica también deberá valorar, ya que a pesar de que la mayoría de ellos puede que se beneficien del principio de intervención mínima y su expediente no dé lugar a un proceso formal, en muchas ocasiones se llevará a cabo un acto de reparación o conciliación con la víctima que ejecutará el correspondiente equipo de mediación. En cualquier caso, el porcentaje de aquellos que reinciden más de dos veces es muy pequeño; varia de un $2,8 \%$ en los más pequeños a un $6,5 \%$ en los de 16-17 años. Estos, que serían los porcentajes de sujetos con una historia criminal muy enconada, no es un dato nada desdeñable, ya que este tipo de sujetos necesitará un tratamiento intensivo.

\section{CONCLUSIONES}

Los datos expuestos nos confrontan con muchas de las creencias que se tienen acerca del fenómeno que conocemos como delincuencia juvenil. En primer lugar, con esos términos nos estamos refiriendo a un volumen considerable de asuntos. Los datos expuestos en las hipótesis sobre el futuro de la justicia de menores así lo revelan; en el caso de la Comunidad de Castilla-La Mancha estamos hablando de 2672 expedientes anuales como hipótesis mínima y de 5340 expedientes como el límite máximo. En segundo lugar, a pesar de la creencia generalizada de que unos pocos son los responsables de todos los delitos, en el caso de los delincuentes juveniles hay un porcentaje elevado de delincuentes primarios, mientras que el porcentaje de jóvenes con carreras delictivas muy consolidadas se reduce a muy pocos casos.

Los menores de 14 años desaparecen del sistema, pero no por ello van a abandonar su comportamiento antisocial, por lo que es de esperar que los servicios de protección deberán también hacer previsiones respecto a esta nueva situación, consecuencia de una opción políticamente adoptada por la Ley sin definir alternativas posibles.

Para concluir si realmente hay una apuesta clara por la justicia juvenil será imprescindible que se le dote de los recursos necesarios.

\section{Boletín Criminológico $N^{o} 47$ Mayo-Junio 2000 Página 4}

